\title{
PROLEGOMENON
}

\section{Subjects as motion}

[T] he best images and parables should speak of time and becoming: they should be a eulogy and a justification of all transitoriness.

(Nietzsche 1969, 111)

It pertains to the essence of becoming to move and pull in both directions at once. Good sense affirms that in all things there is a determinable sense of direction; but paradox is the affirmation of both senses or directions at the same time.

(Deleuze 2001, 3)

Guntur was a 25-year-old single man I befriended in the late 1990s in the town of Probolinggo, a beautiful and serene coastal small town in the province of East Java. As was the case with most town residents, Guntur was a fluent speaker of both the Javanese and Madurese languages. He had acquired these languages from his father, a retired civil servant who had come to Probolinggo from Surakarta in Central Java some thirty years before to take up a post in the local branch of the Department of Agriculture, and from his mother, a Madurese vegetable seller originally from the market town of Pamekasan in the adjacent island of Madura.

Guntur's parents' life stories are typical of many of the town's inhabitants. Their biographies as well those of many others are marked by migration, the movement away from their places of origin, commonly located in other parts of Java and in Madura, and centre on a conjunction, a coming together that is best conveyed in the emphasis people place on finding a job and a spouse, having children and prospering in the small town of Probolinggo.

At home, Guntur's Javanese side was actively cultivated by his father, an avid exegete of Javanese 'custom'. He schooled all of his four children in Javanese language, teaching them its low- and middle-level speech levels, and passed on to them his enthusiasm for puppet-theatre performances (wayang kulit, Ind.). Despite being unable to follow the high-level speech employed in such 
performances, Guntur, who was a student of economics in the local university, used to spend his Saturday evenings in the company of university friends watching televised puppet-theatre performances together and talking about them with much enthusiasm. I would often join this company and get drawn into the adventures of the characters discussed, especially those of Arjuna that held so much fascination for my interlocutors. The friends' approach to puppet theatre, its characters, and performances is indicative of wider engagements with the art form carried out by locals and anthropologists of Java alike. According to such engagements, wayang kulit exemplifies all that the category of 'Java' is about. This 'Java' Guntur and his friends would often describe as being bound with the quality of halus (Ind.), a dispositional and affective capacity for acting with eloquence, refinement, humility and circumspection towards others with which the Javanese are held to be endowed.

At the same time, Guntur had a discernible Madurese side to him which his relationship with his mother supported and sustained. Despite speaking Javanese to his father at home, he, his mother and siblings would converse in Madurese, deploying the lower speech level deemed appropriate for such intimate relations, it being only one they commanded. In addition, Guntur would often use low Madurese with some of his neighbours - while engaging with others in Javanese - as well as with the traders, both male and female, in Probolinggo's central market where his mother was making a living as a vegetable seller and where he acted as her trusted assistant. The employment of low Madurese in the market context as the instantiation of Guntur's Madurese side was accompanied by his movement and speech acquiring a certain assertiveness, forcefulness and even combativeness that turned his dealings with the other traders into an event with visible losers and winners. Bargaining hard over prices, a common practice in which Guntur excelled, was accompanied by humour and joking, often crass, obtuse and filled with sexual innuendo, which traders enjoyed participating in often at the expense of one another. Gundur's habitual style in the market involved the deployment of a series of distinct dispositions and affects which are locally qualified as kasar (Ind.); that is, coarse, unrefined, boastful and fierce. Such affects and manners of orientation are closely associated across Java with the category of 'Madura' and with the people that inhabit this arid island located just off the eastern coast of Java and across a narrow strait.

Condensed in these recollections of Guntur as an actor embedded in relationships and moving transversally across varied contexts and situations is the key theme this book addresses: namely what are we as anthropologists, social scientists or humanities scholars to make of people like Guntur who, rather than being endowed with a given, singular identity, are differentially actualized and constituted as a result of the relationships in which they 
participate? Somewhat differently put, the central question this book raises and seeks to answer is how are we to conceive of individuals such as Guntur who, despite their obvious givenness due to being veritably produced out of specific relationships such as those of filiation, friendship and trading, move (and are moved) in opposite directions, avoiding mere repetition and affirming difference?

Guntur's capacity for actualizing both the categories of 'Java' and 'Madura' in the modes of his behaviour and with regards to specific relations pose considerable challenges to our thinking of the person as an individual endowed with an identity. The becoming-Javanese and becoming-Madurese that Guntur participates in are marked by an indifference towards the assertion and achievement of 'identity' and instead foreground personhood as entangled in a process of endless transformation. The subject these becomings enunciate is thus transitive and more akin to a verb rather than a noun, closer to the unfolding of a process than to the manifestation of an essence. This is so for Guntur's person is motivated neither by choice nor by interest. Both choice and interest involve the positing of the subject as determined in advance and with a priori knowledge of who he/she is. For such a subject, social relations are assumed to be exterior and of secondary importance as it is taken to correspond, first and foremost, to pure, disembodied consciousness. In contrast, Guntur is a self-differing person in the sense that the process he is involves movement in opposite directions with his becoming-refined implicating his becoming-coarse. Such a person I call diaphoron, for it is constituted on the grounds of an irreducible difference that animates and motivates it. The diaphoron person is devoid of unity either dialectically or transcendentally achieved for it is always in motion and already a becoming. As becoming it differs constantly from itself.

Guntur is halus now, kasar before; Javanese tomorrow; Madurese yesterday. To the extent that we differ constantly from ourselves, difference assumes a positive form of relationality that cannot be negatively defined as the lack of self-similarity without letting difference's ontological and sociological potential slip like water through our hands. This potential is more productively taken hold of and realized when we take difference as guiding the relationship articulated between becomings. For Guntur, the becoming-refined and becoming-coarse can indeed be grasped as exclusive alternatives - Guntur is either Javanese or Madurese, this person is either man or a woman, this woman is either a wife or a sister. However, this is a conceptualization imposed on us by thinking in terms of individuals as singular and of identities as given. The end result is for identity to be seen as original and difference as derivative; for relationships to become exterior and secondary, while self-identical individuals are taken as primary. But if we are to do justice to ethnographic encounters and the surprises they entail, which constantly throw us off balance in the 
field, if we are to situate ourselves in precisely those moments of surprise and wonder and seek to recover and seize on feeling off-balance for the purpose of anthropological analysis, then ethnographic descriptions can be neither straightforward nor retain an aura of persuasiveness rooted in the evocation of the familiar and the common.

What this book aims to achieve is to do justice to my ethnographic encounters with Guntur and the people of Probolinggo that unfolded during 18 months of fieldwork from October 1998 to March 2000, as well as during subsequent visits to the area, the more recent in the summer of 2010. Such an endeavour demands that Western metaphysics are bracketed and the positing of the individual as an autonomous, self-identical, indivisible and naturally given entity is interrogated as a figure that has been produced (and is still being produced) by at least two centuries of religious disenchantment, labour alienation, democratic representation, and biomedical organicism. There is no reason, however, to repeat here the uncomfortable and counterintuitive lessons Nietzsche's $(1967,1969)$ and Foucault's $(1973,1979)$ genealogical readings of Western science, philosophy, and morality have taught us. ${ }^{1}$ There is equally no reason for going over the significant contributions of Mauss (1985) and Dumont (1986), which have shown us from a different perspective and with unparalleled insight the culturally peculiar and historically contingent status of the self-identical and self-interested individual in the record of human diversity. The Industrial Revolution, the capitalist definition of goods as commodities and of markets as a separate domain of social action, taken together with the ideals of the European Enlightenment have had a profound influence on the way we understand the person. Conceived as an individual, this way of understanding the person corresponds to a key presupposition that critical

1 In On the Genealogy of Morals, Nietzsche laments the fateful accidents that grammar introduces to thought: 'only owing to the seduction of language (and of the fundamental errors of reason that are petrified in it) which conceives and misconceives all effects as conditioned by something that causes effects, by a "subject", can it appear otherwise' $(1967,45)$. The overcoming of language necessitates for Nietzsche a strategy that is best exemplified in his concept of eternal recurrence. If the putative givenness of the subject is rooted in the misrecognition of an effect of forces as the ultimate cause, then, he asserts, the willing affirmation and enthusiastic embracing of the subject as an effect opens up and activates a new figure. This new figure that Nietzsche calls the over-man is not so much a negation of the human as we know it but a reconceptualization of it as a becoming, an effected 'entity' that is capable of acting only on condition of this very affirmation. Both Foucault's conception of the subject as discursively produced and to anticipate what follows, Deleuze's emphasis on becoming form further elaborations of Nietzsche's critical insights. For a short summary of the convergences and divergences of the work of these philosophers, see Colebrook (1999). 
scholarship has elicited as foundational to Western metaphysics. This and other unnatural givens, such as the culture-nature, subject-object, moderntraditional, individual-society distinctions, require no further explication as to their pervasiveness in the West (Latour 1993; M. Strathern 1988; Viveiros de Castro 1998). What requires rehearsing, however, is 'becoming' and its own modality of producing the given. Lest I am accused of drawing too rigid a distinction between the West and Java, let me try to loosen it with an amusing example that will throw further light into the relation that becoming privileges.

Lewis Carroll's (2006) heroine, Alice, follows a white rabbit down a rabbit hole and finds herself in Wonderland, a place in which nothing is as it seems. Here not only are animals capable of language and suckling babies turn out to be pigs - these ideas are, after all, well known to anthropologists working in Southeast Asia as well as beyond - but the magic contained in cakes, potions and mushrooms allows Alice for the first time to experience and undergo profound transformations with her size shooting up and down 'like a telescope', shrinking to ten inches short and growing into the dimensions of a full-blown house, and vice versa.

Alice is Gilles Deleuze's favourite heroine, too. In The Logic of Sense (2001), Deleuze uses Carroll's books as an opening to his exploration of the makings and un-makings of sense and non-sense. What Alice's adventures amount to, according to the French philosopher, is the foregrounding of becoming as an unlimited, infinite process that the virtual place called Wonderland privileges, calling for the liberation of difference from its subordination to identity as prior and given. This is how Deleuze 'reads' Alice:

All these reversals as they appear in infinite identity have one consequence: the contesting of Alice's personal identity and the loss of her proper name. The loss of the proper name is the adventure which is repeated throughout Alice adventures. For the proper or singular name is guaranteed by the permanence of savoir. The latter is embodied in general names designating pauses and rests, in substantives and adjectives, ... But when substantives and adjectives begin to dissolve, when names ... are carried away by the verbs of pure becoming and slide into the language of events, all identity disappears from the self, the world, and God. (2001, 5; italics in the original)

In Wonderland, Alice's identity/size is subject to fluctuation and reversal; she is becoming smaller than she is now and is bound to become larger later. She is certainly not larger and smaller at the same time; her becoming is a differential relation that unfolds through her moving and pulling in two directions at once with her size eluding both stability and the present. Alice is precisely a 
diaphoron person, a self-differing person as she does not grow without shrinking and does not shrink without growing. Her size in any given moment does not correspond to a prior or original identity, rather is only a pause and a rest; such pauses and rests are derivative of the transitive process that her unending becoming amounts to.

What Carroll and Deleuze invite us to ponder is Alice-as-becoming. Such becoming is the person, a person that constantly differs from itself. At the same time, they insist on seeing Alice's proper name, i.e. her identity, as a secondary principle produced by the unfolding of difference. In this regard, Alice's becoming is best conceived as a relation between reciprocally presupposed differentials. Let me explain: in this scheme, 'small' is not the opposite of 'large' and 'large' does not amount to the negation of 'small'; difference is not conceived as a relation between two terms each of which is endowed with a prior identity. Rather, difference is the ontological ground of unlimited becoming and the means by which the empirical diversity of sizes, forms and identities is given. ${ }^{2}$ The inversion of the order of priority of difference and identity effected in this way is complemented by Deleuze's reworking of what appear to be oppositional terms and contradictory phenomena into immanent dimensions of becoming; that is, equally necessary and mutually implicated aspects of a single process with one term 'always concealed by the other, yet continuously coming to the aid of, or subsisting under, the other' (2001, 4). Alice's operation 'like a telescope' offers no better image of the dynamic co-implication of small and large as her larger size subsists under and inheres in her smaller frame, and vice versa.

As the unfolding of a process, becoming is, for Deleuze, synonymous with two operations: as well as constantly working towards the disaggregation, or deterritorialization if you prefer, of any given form Alice takes, causing

2 Becoming is a difference-driven process 'by which the given is given' (Deleuze 1994, 222). The given, Deleuze tells us in Difference and Repetition (1994) must be understood as a secondary operation under which difference is pressed into temporary forms and multiplicity is translated into singularity. His philosophy thus rests on a consideration of the morphogenetic processes that create individuated forms out of differential multiplicities. These processes, which are both unstable and reversible, are discussed on the basis of a tripartite ontological scheme that posits three closely interrelated planes: the virtual, the intensive, and the extensive. By means of the mediation of the intensive, the multiplicities that organize the virtual become actualized in the extensive as the distinctive and singular forms we take for granted. At the same time, however, a reverse process is always in operation which acts to disaggregate and detotalize what is already given before a new cycle of formation/production takes hold. The political implications of these notions are worked out in the two volumes of the Capitalism and Schizophrenia project, Anti-Oedipus (1977) and A Thousand Plateaus (2004), that Gilles Deleuze co-wrote with Félix Guattari. 
her to be swept and carried away, reeling her into different shapes, it also passes through all of these shapes while connecting them disjunctively, i.e. through affirming their difference. Becoming is therefore nothing more, and nothing less, than a specific kind of relation, a particular mode of relating differentials; it is, in other words, 'a positive principle of relationality, meaning both disjunction and connection ... rather than a merely negative want of similarity' (Viveiros de Castro 2009, 245.) Small and large are thus not only reciprocally presupposed as immanent dimensions of a process but are also intrinsically connected to each other through their processual unfolding. The relation becoming privileges therefore amounts to a disjunctive synthesis or a pairing of two terms with each term providing the context and the ground of the other. As such, becoming is not to be conflated with the Hegelian dialectic that operates by synthesizing two opposing terms into a higher or superior unity, itself accomplished by the positing of a third term which manages to contain and thus overcome the earlier opposition. Indeed, Deleuze (1994) explicitly denounces the dialectic as subordinating difference to identity, process to stasis, and becoming to being. Alice by contrast forces us to take her self-differing seriously and without recourse to a superior unity invites us to see difference at the very heart of being as infinite becoming.

In a way, all that the current book is about is already here: the becomingJavanese and becoming-Madurese of Guntur are running in parallel with the becoming-smaller and the becoming-larger of Alice. In both cases, the person is a becoming and thus differentially actualized in accordance to the contexts and relationships in which it is embedded. Immanent in these actualizations are two sides, each of which subsists under and inheres in the other even as one side is concealed and hidden from view in favour of the other which in the course of events comes to be revealed and made known. The categories 'Javanese' and 'Madurese', 'small' and 'large', thus do not amount to exclusive alternatives but to mutually implicated lines of movement, the trajectories traced by the person as it unfolds and is unfolded. This person I refer to as the diaphoron person.

The diaphoron person is elusive due to the multiplicity of the shapes it assumes, yet its presence is both definite and distinctive. Its transitive temperament, due mainly to the never-ending processes of transformation it participates in as an effect is coupled with it being veritably agentive. Both this and that, the diaphoron person resists the assignation of cross-contextual and atemporal identity, for it is an assemblage made of differentiated parts. Such parts are often coded in Java as differential dispositions, affects and capacities. Made up of and moving towards both Java and Madura, the past and the future, the feminine and the masculine, the higher and the lower, the human and the non-human, alternately and successively, the person I wish to designate as such 
is conditioned by a fundamental, irreducible difference - i.e. made up by an internal alterity - which, as we shall see shortly, furnishes the very grounds of its sociality.

In this book, the diaphoron person is a figure of thought through which I am attempting to explore the uncommon conditions of possibility of the person. In this thought experiment, the figure of the diaphoron person is emergent, evolving out of my involvement in long-term fieldwork in the East Javanese town of Probolinggo and of my wonder and constant bafflement regarding the events, relationships, and activities I saw people there engaged in. The diaphoron person also bears the implications of my own participation in such events, relationships and activities as a relatively young and unmarried male researcher, who conducted the majority of his research while residing in a small Islamic boarding school in the town's periphery. The concept of becoming that I explore here is hence intrinsically related to my own experiences during fieldwork. These I have narrated elsewhere (Retsikas 2008) as involving a process of becoming a moral Muslim subject despite having not converted to Islam. In a sense then, my own trajectory is echoed here in the very descriptions and concepts I am advancing and employing to render my interlocutors' personhood communicable to an audience unfamiliar with Java. At the same time, the figure of the diaphoron person is also embedded within a set of views provided by the library, having grown out of subsequent engagement with anthropological and non-anthropological literatures. As such, the diaphoron person is also a product of scholarly imagination, the parameters and overall problems of which are not to be conflated with those of my informants. Within my shifting back and forth between personal experiences, scholarly commitments, and what properly belongs to my fieldwork friends, neighbours and acquaintances is the very necessary and inescapable analytical movement of any ethnographic monograph as an assemblage of heterogeneous elements. This book is therefore not only about the diaphoron person but is diaphoron itself.

\section{Becoming}

It is perhaps impossible to write about Java, or Indonesia for that matter, without having to come to terms with Geertz's monumental work on the subject. This is due to Geertz's unparalleled influence on the ethnography of the area but also because it is often the case that people in Java seem only too ready to explicate themselves to foreign tourists and anthropologists alike through the very same categories and conceptual connections that Geertz established as paradigmatic. While his tripartite division of the Javanese religious landscape is well known and widely accepted by many educated Javanese, every student of 
anthropology at one point or another has had to cut his/her teeth by engaging with Geertz's classic essay 'From the Native's Point View' (1993). While the text is often taught as a critical response to the Malinowskian privileging of empathy as the very basis of anthropological knowledge, it is more directly concerned with elucidating alternative conceptions of the person to the Western one.

In his unique writing style and highly relativistic manner, Geertz's starting point is:

The Western conception of the person as a bounded, unique, more or less integrated motivational and cognitive universe, a dynamic centre of awareness, emotion, judgment, and action organised into a distinctive whole and set contrastively both against other such wholes and against the social and natural background, is, however, incorrigible it may seem to us, a rather peculiar idea within the context of the world's cultures. $(1993,59)$

To this odd conception that foregrounds uniqueness in an era of mass production Geertz counter-opposes a triadic set consisting of Javanese, Balinese and Moroccan conceptions of the person that differ markedly and dramatically both from one another and from the Western one. While the Moroccan way of conceiving persons grounds them in relational contexts and proceeds by way of arranging them in a series of nested categories, one more inclusive than the other, and the Balinese seem to view the person as an de-individuated performer in a theatre of status distinctions in which very exact positions are statically filled by subsequent generations, the Javanese view of the person revolves around two sets of contrasts that finding no resolution or integration into a higher order result in 'a bifurcate conception of the self' (1993, 61).

While Moroccans and Balinese in their different ways go about insisting that the person is social in the sense of being always already enmeshed in social relations, Geertz suggests the Javanese divide the person up by means of a two-fold partition. No longer an undifferentiated whole, the person is conceived as split in four. These partitions Geertz relates interpretatively both to the conceptual division between the 'inside' (batin, Ind.) and the 'outside' (lahir, Ind.), the emotional life of the human person versus his/her outward behaviour, and to the distinction between the 'refined' (halus) and 'vulgar' (kasar). The relationships between the two divisions are quite complex and can be summarized as follows. Batin and lahir correspond not only to highly autonomous, separate and independent realms of the person but are also thought of as in need 'to be put in proper order independently' (1993, 61). In this connection, the second pair comes into play with the goal being to avoid acting 
with vulgarity and coarseness, striving instead towards achieving refinement, subtlety and smoothness both inwardly and outwardly. The primary means for accomplishing this coveted goal involve firstly, the undertaking of religious regimes of asceticism that smooth one's batin and secondly, the regularization of lahir through conforming to social rules of etiquette. However effective the ordering of batin and lahir is, the person remains nevertheless the locus of dissonance as the difference between 'inside' and 'outside' can be neither surmounted nor displaced. Thus Geertz concludes that for the Javanese

An inner world of stilled emotion and an outer world of shaped behaviour confront one another as sharply distinguished realms unto themselves, any particular person being but the momentary locus, so to speak, of that confrontation, a passing expression of their permanent existence, their permanent separation, and their permanent need to be kept in their own order. (Geertz 1993, 61)

Geertz's analysis of Javanese ontology - this is the term he himself uses - as premised on split subjects and foundational divisions is carried forwards in this book by the concept of the diaphoron person. The diaphoron person, I have already argued, is to be understood not as the site and source of a pre-given identity but as an unstable and shifting subject permeated by and constituted by means of difference, a self-differing person that assumes a multiplicity of forms which correspond to the pauses and rests of unlimited becoming. If this carrying forward exercise is to take effect, however, both Geertz's interpretative style of analysis that coheres around the cross-cultural translation of concepts as the differential representations of an objectively given and shared world and his emphasis on anchoring such representations to a sole theme - theatre in Bali, nisba in Morocco, dissonance in Java - need to be approached with caution. For what we are dealing with here is certainly not representations or worldviews but presuppositions and assumptions that belong to worlds that are differentially constituted and lived. ${ }^{3}$ In order for us to better grasp these disparate worlds, it is not enough to simply emphasize different concepts. We have to rethink and reconceptualize difference itself, inclusive of culture difference. To this end, it is also necessary to avoid reducing the complexities of what we encounter in the field to a few principles, themes or foundations that act as metonyms for what is veritably a much more open and undetermined field.

3 As Viveiros de Castro puts it, 'the problem is not that Amazonians and Euro-Americans give different names to (or have different representations of) the same things; the problem is that we and they are not talking about the same things' (2009, 241). On the limits of cross-cultural translation, see also Retsikas (2010a). 
While the present book makes no claims regarding the first task, i.e. the reconceptualization of culture difference, it nevertheless aims to show that the diaphoron person is not simply the result of the operation of two sets of 'contrasts' but a figure one runs into in a manifold of social plateaus. As such, it is neither simply anchored in nor merely reducible to a determinable and knowable set of factors, themes, or causes. Instead the diaphoron person will be shown in this book to proliferate acentrically in all kinds of directions and to thrive in a plurality of local ideas and practices that in turn have to do with what we conventionally call ethnicity, kinship, religion, sorcery and place. In addition to having two sides, one of which is eclipsed and the other revealed as a result of particular encounters and relations, the diaphoron person is also a multiplicity, containing within itself an assorted set of differences, with its form changing every time it crosses over and moves from one plateau into another.

In the plateau of ethnicity, the diaphoron person of East Java is stabilized as an assemblage of Madurese and Javanese parts. These parts are themselves related to the halus-kasar hierarchical distinction Geertz mentions above. The distribution of such parts among the current inhabitants of Probolinggo is intrinsically related to the demographic history of this part of Java - discussed in Chapter 1 - that during the nineteenth century saw large numbers of Javanese and Madurese migrating into, taking up residence in and making a living out of its resources that related principally to land and its products. Subsequent intensive processes of inter-ethnic marriage and of spatial intermingling in ethnically mixed neighbourhoods along with extensive and widespread patterns of exchange of food, prayers, and ancestors among the migrants and their descendants have contributed towards the self-identification of today's inhabitants as 'mixed people' (orang campuran, Ind.), i.e. as a people who are disjunctively connected both to 'Java' and to 'Madura'. Among the key contentions of this book, set out in Chapter 2, is the argument that this mixing has neither cancelled out nor displaced the distinction between Javanese and Madurese but has worked so as to foreground difference as constitutive of the experience of locals' sense of self. To be mixed, in other words, does not amount to the superseding of the hierarchy that marks the relation between the categories of 'Java' and 'Madura' and the people these categories are associated with. Quite the contrary is true. As I have shown before (2007b) and argue again here, ethnic difference is re-inscribed from a new and innovative point of view, that of mixed people that strive to portray themselves as the occupants of the apex of hierarchical pyramid in their capacity to act both in Madurese and Javanese ways and manners.

In the plateau of sorcery, the elements that make up the diaphoron person change and involve the unstable assembly of masculine and feminine capacities 
and affects therein. As every ethnographer of Java knows only too well, sorcery is a pervasive and constant concern among the peoples of this most densely populated island. In general, sorcery is intrinsically connected with acute anxieties and fears regarding the true intentions and feelings of significant others and intimates that includes ones' kin, neighbours, friends and work colleagues. The book's excursion into sorcery ideas and practices undertaken in Chapter 6 is carried out with the explicit aim of showing that the person is locally understood as an internally differentiated being also with respect to gender. In all respects and purposes, it is conceived as an androgynous entity that becomes singularly male or female in view of the specific relations it enters, voluntarily or not. In the case of sorcery, as in the case of ethnicity remember the example of Guntur - what we often take to be formally opposed characteristics (male and female) are locally conceived as reciprocally implicated and presupposed terms, with masculinity held to subsist under and inhere in femininity. The internal gender difference that makes up the person along with its transformability from male to female, and vice versa, is the very ground on which sorcerers conduct their business. Their techniques are thus uniquely designed to use both such gendered difference and such becoming for their own and their client's advantage through the delivery of misfortune, pain and death to their intended victim whose gender, in the course of sorcery rites, is made to change from male to female; that is, from relatively closed and invulnerable to relatively open, porous, and susceptible to attack.

Quite paradoxically, sorcery's efficacy, I argue, stems partly from the evocation of weddings and marriage transactions as the fee the sorcerer's client submits to the sorcerer is construed as mahar (Ind.; mahr in Arabic; also referred to as mas kawin), an essential part of the validity of any marriage contract according to Islam that both Madurese and Javanese profess in their vast majority. The practice of mahar corresponds to the zone of indiscernibility as far as the differences that organize the plateaus of sorcery and kinship are concerned. Mahar is the threshold, the door that leads from sorcery to kinship and back; it is their intersection, the borderline on which the differences that make them up meet, communicate and cross over; it is the thread that ties such differences and plateaus together.

In distinct Southeast Asian fashion, persons in Probolinggo are conceived in sibling terms. Indeed, one of the three most important questions any newcomer in the area is asked to provide information about is how many siblings one has - the other two being where does one come from and whether he/she is married. The right way to answer this question is to include oneself in the counting, that is to render oneself as part of a set (of two, three, four, etc.) siblings and often to designate one's precise position in the set in terms of birth order, i.e. first, second, third, etc. The conception of person as part of a set, 
I argue in Chapter 3, presents a number of interesting features. Firstly, the emphasis placed on the set is strongly associated with the identitarian union of siblings who are thought of as being and acting as one, in accord with reference to similarly constituted sets. Sibling unity is best exemplified and actively cultivated by the siblings' sharing a common set of progenitors, a common dwelling and a hearth, having access to a commonly held property that is yet to be allocated, etc. (see Carsten 1997; Errington 1987; Freeman 1970). Indeed, locals of Probolinggo place great emphasis on both the values of solidarity and co-operation that are said to permeate sibling relations and on the feelings of love and care that animate and motivate such values. At the same time, however, such a set is unequivocally conceptualized as dividable, with the operation of the incest taboo ensuring the parting of the members of the set. This divisibility, which is fully actualized with marriage and the distribution of the parents' property between the parties involved according a variety of rules and preferences, corresponds to a latent presence that always and already 'haunts' the unity of the set. Indeed, in Probolinggo as well as in numerous other societies in the Indonesian archipelago birth order more than gender arranges the set of siblings according to precise relations permeated by hierarchy, and thus, by difference. The singularity that sibling sets form, in other words, is both contingent and unstable for it is subject to processes of dissolution and separation the first effected by marriage and the second by means of the internal relations of hierarchical difference that regulate behaviours between birth order juniors and seniors. It goes without saying that such behaviours are equally elaborated in Java as involving the demonstration of respect and deference younger siblings owe older ones, and the duty of care and personal sacrifice even that elder siblings owe their younger brothers and sisters.

In Chapters 3 and 4, I reflect on the very important literature on kinship in island Southeast Asia. Taking inspiration from Lévi-Strauss's notion of the House (1988), I argue that sibling sets instantiate the diaphoron person in the plateau of kinship. The person the set so designates is pure becoming for two reasons. The first relates to what has been said above, i.e. the entanglement of the processes of singularity formation and hierarchical separation and dissolution that constantly evoke each other forth, corresponding to two sides of the same phenomenon. Such processes are never ending as each particular sibling set is but a momentary pause and rest of all those sets preceding it and flowing from it, a point that Errington eloquently conveys in observing that 'relationship terminology [in Southeast Asian islands] arranges people into [past, present, and future] layers of siblings' (1987, 409).

The second reason for siblingship realizing the diaphoron person is that it amounts to a very particular, very special topos as it connects affinity with 
descent, and vice versa. The way this is achieved involves both mythology and ritual praxis. In common with several other Southeast Asian island societies, Javanese mythological accounts of the world's founding tell of the story of the very strong attraction between a heavenly pair of brother and sister, of their forced separation, and of the gift of rice agriculture that the sister made to humanity. The myth, I argue, forms the background for the conduct of wedding rituals which are dedicated to fashioning the bride and the groom into younger sister and elder brother respectively, something that is both reflected and enforced by the deployment of the relevant kinship terminology that remains in place at least until the first offspring arrives. Condensed in the relationship of siblingship, therefore, is an alternative conceptualization of the social that previous anthropologists working in the region have done well to emphasize though not fully explore. This alternative conceptualization my argument is gives primacy neither to the doctrine of descent as vertical encompassment nor to the principle of alliance as reciprocal recognition. What the conceptualization of the social in terms of siblingship does is to highlight the links that connect descent to affinity and the processes of their mutual convertibility. More than anything else, siblingship brings attention to the becomings which persons must undergo as a precondition for the achievement of reproduction, fertility, abundance, profusion, excess and life itself. To the extent that siblingship is synonymous with the attainment of abundance, abundance is contingent on the person being seen from the outset and forever as a member of a divisible set and/or part of a dissoluble pair. The referential capacity of this pair is not limited to relations pertaining among the offspring of a couple but in a distinct fashion encompasses the relations that organize and make up the couple itself.

The becomings that the incest taboo and siblingship set in motion do not exhaust local conceptualizations of the person however 'constraining' and specific they might be for every anthropologist working on island Southeast Asia. The unstable assemblages of discrete and hierarchical parts that sibling pairs form are supplemented - in the double sense of the term as addition and displacement (see Strathern 1999, 238) - by other, equally contingent assemblages one readily encounters in the plateau of religious devotion. Much has been written about the place and relevance of asceticism in Java. The works of Anderson (1990) and Keeler (1987) have done much to illuminate both the links that the Javanese establish between religious asceticism and power, on the one hand, and between abstinence and selfhood, on the other. In particular, Keeler's argument about the Javanese ideal of selfhood is highly pertinent for my purposes. Keeler shows how the Javanese sense of self revolves around the vagaries, risks and dangers everyday encounters entail, on the one hand, and, on the other, the promises of unsurpassable 
self-assuredness, safety and ascendancy that asceticism is credited with bringing about. Asceticism, he writes, 'is a kind of reaction to the vulnerability people sense in encounter' $(1987,49$, n.10) with the decision to disengage from the world being the result of an attempt to temporarily escape the incessant negotiation of status distinctions affected by, and manifested in, among other things, speech level use. Stepping out of the uncertainties of everyday encounters and getting engaged in silent meditation, Javanese men as well as some women willingly undergo ascetic practices inclusive of fasting and abstaining from sex, with the explicit aim that the more one suppresses one's desires and the more one is without selfish interest, the more one will be capable of defining, or imposing upon, other people one's own speech, wishes and claims.

Perhaps Keeler has overstated the extent to which 'encounter and asceticism [are] two opposite and complementary modes of action' (1987, 49). As I endeavour to show in Chapters 5 and 6, ascetic regimes do involve encounters with non-human beings that can be equally risky and dangerous as well as very promising in terms of accruing beneficial outcomes. Chapter 6 ventures into a consideration of the hazardous nature of social relationships established with non-human beings while Chapter 5 takes a close look into narratives associated with the acquisition of the capacity to heal by people who subscribe to traditionalist, Sufi-inspired modes of Islamic piety. East Java, within which Probolinggo is situated, is widely and validly considered as one of key strongholds of Nahdlatul Ulama, Indonesia's largest Muslim organization that is centred upon the figure of Islamic scholars (kyal) and networks of Islamic boarding schools (pondok pesantren, Ind.) similar to the one I found myself living in for more than a year. My close acquaintance with such figures and such traditions is conveyed in the narratives of two people who are locally renowned for their abilities in dealing successfully with the troubles and misfortunes that afflict humans. Such healers are endowed with what I argue can productively be thought of as heterogeneous assemblages of human and non-human parts and elements that are intensively connected through circuits of relations that ascetic regimes of religious devotion foster and maintain. The difference, on the basis of which such persons are constituted, is traceable to processes of becoming-sacred. Such processes are transformational as they involve the voluntary and temporary annihilation of the human and are accompanied by gifts of divine grace as semi-permanent attachments and additions to the make-up of the healers' bodies. Such non-human attachments are furthermore subject to detachment and circulation that proceed by means of both commodity logic and exchange relations in terms of their transmission to other human recipients who then become able to perform healing with a variety of degrees of efficacy. 
The themes that the current book deals with are offered as an incitement for us to reflect on the implications this multiplicity of differences has for the diaphoron person as it, and the accompanying ethnography, crosses over from one plateau to the other. In a way, the current book is an old-fashioned sort of ethnographic monograph. I make no apologies for evoking here a certain ideal, that of a total ethnography which guided many anthropologists working during the discipline's classical era. Evans-Prichard's The Nuer (1969) and Leach's Political Systems of Highland Burma (1970) provide perhaps the most iconic examples of such a programme of study, containing descriptions and analyses of a bewildering variety of materials that encompass almost everything from ecological conditions and modes of livelihood to material culture, kinship and political systems, religious practices and ethnic relations. Beyond the crude and unreflexive functionalist 'cutting' of the social into distinct institutions and the simplistic task of organically relating back what had previously been rendered separate, beyond even a certain encyclopaedic ambition to match the ambitions of colonial governments, there was, it has to be finally admitted, among anthropologists of that generation an admirable lack of certainty about what was important to the people one studied with, and a marvellous dearth of a priori convictions about what constituted politics, or kinship, or economy in such faraway places. This was a moment of aporia that I want to recapture and redeploy.

During my fieldwork I had the privilege of finding myself with plenty of time to spare and this plenitude was matched with the generosity of the people I worked with who were more than willing to put up and assist with my rather awkward queries. For this I will be eternally indebted. Due to circumstance and good intentions then I was able to follow diverse lines of inquiry and diverge into all sorts of concerns, most of which have found their way in this book. However, the total ethnography I advocate here for is quite different from totalizing ethnography. Whereas the former is an exploration that moves laterally and stays on a level, flat surface, comparing and contrasting phenomena so as to evince their characteristic ways of diverging, the latter moves vertically and seeks to reach deep into unfathomable depths so as to unearth and extract the factor(s) that make things the way they are. In other words, whereas total ethnography is concerned with mapping the movements and the transformations incurred on such flat plane of a 'thing' that differs constantly from itself, totalizing ethnography is characterized by its recourse to an extrinsic element or a supplementary dimension that gives the observed phenomena their organic unity and organizational coherence (see Viveiros de Castro 2010). The systems the two approaches are therefore designed to set up are largely incompatible and irreconcilable. Total ethnography's complexity is related to describing both the processes of assembly and disassembly that 
permeate the empirical phenomena under consideration as encountered in each specific plateau, and the trajectory their crossings over various plateaus trace. In contrast, totalizing ethnography's complexity is connected to determining the system's transcendent unification by the operation of a limited number of principles. While the former conserves our aporia and leads to an opening that is directly associated with difference's acentric proliferation which is going all the way down, so to speak, the latter ends up projecting closure and certitude through the identification of the found and its naming. For all their brilliance therefore Evans-Prichard's 'discovery' of a Nuer politics conducted by means of lineage corporate groupings, and Leach's alternative of Kachin affairs organized around the oscillation of hierarchy and equality as the horizon and end point of anthropological inquiry simply won't do us any more.

For beginning from and staying with aporia, starting from and conserving wonder it is necessary to tear the person up and to keep it open. The first move involves paying attention to its becomings; such becomings are associated with the two reciprocally presupposed sides that the person consists of and their alternate manifestation in the process of forming relations with other persons in the space defined by particular plateaus. As an assemblage of heterogeneous elements, the becomings which diaphoron persons undergo therein are related to the person shooting up and down 'like a telescope', revealing this side and eclipsing the other, becoming male now and female later, Madurese yesterday and Javanese tomorrow, acting externally in sibling unison or in accordance to internal hierarchical distinctions. The relation between reciprocally presupposed differentials that the concept of becoming encodes is, however, only half of the story. In order to keep the diaphoron person open, and our curiosity amplified rather than satisfied, a second move is equally required. As Deleuze and Guattari have put it in the fabulous Chapter 10 of their $A$ Thousand Plateaus (2004), it is also necessary to focus on the transversal relations pertaining among plateaus, the diagonal connections among the different sets of heterogeneities that make the diaphoron person up. This analytical move amounts to a further instance of foregrounding becoming, a becoming articulated in the intersections of assemblages, the zones of indiscernibility the meeting of two or more multiplicities sets up.

For Deleuze and Guattari, there is very little difference between the concepts of becoming and multiplicity. Indeed, they write that

becoming and multiplicity are the same thing. A multiplicity is defined not by its elements, nor by a centre of unification or comprehension. It is defined by the number of dimensions it has; $\ldots$ it cannot lose or gain a dimension without changing its nature. Since its variations and dimensions are immanent to it, it amounts to the 
same thing to say that each multiplicity is already composed of heterogeneous terms in symbiosis, and that a multiplicity is continually transforming itself into a string of other multiplicities, according to its thresholds and doors. (2004, 275; italics in the original)

Becoming therefore summons the relations between the immanent assemblages as the latter continually transform themselves into each other, cross over into each other. The assemblages in question correspond to the various dimensions of the diaphoron person explored in this book in relation to specific themes organized in terms of separate chapters. Becoming, however, exceeds and surpasses such separations and purifications by means of the curve a discontinuous, broken line draws. This excess, which Deleuze and Guattari (2004) variously name as 'line of flight', 'the Body without Organs' and 'rhizome', has certain unmistakable effects; it both sets out to destabilize and deterritorialize the temporary and concrete forms the diaphoron person assumes in each specific plateau and to push or carry its becomings forwards and onwards onto new plateaus where fresh processes of form giving or territorialization are bound to begin their work. This second instance of becoming bound as it is with crossings-over is all about unhinged growth, immense proliferation, and lateral profusion. They argue that the rhizome 'assumes diverse forms, branches in all directions, and forms bulbs and tubers. [It] is multiple, giving rise to its own structure but also breaking that structure according to the "line of flight" it contains' (quoted in M. Strathern 1995, 21). It is in this sense that becoming achieves to generate and permeate everything there is and to present the best image of being we can hope for getting at.

Becoming as 'line of flight' not only keeps difference intact but its registered transversal movements have the capacity to increase difference exponentially. Becoming does not correspond to a singular entity nor does it present a type. It is neither an indivisible unity nor a static aggregate of assemblages but always an evolving difference-in-itself. As its trajectories push the assemblages it consists of towards change and transformation, so too the connections and relations becoming creates among them make it to differ constantly from itself. The more crossing over takes place the more passages through assemblages are accomplished; the more connections are generated the more differences are produced. The unlimited character of becoming brings about the unbounding and multiplication of difference as an internal and immanent dimension of the diaphoron person, and opens the door to aporia and astonishment once more as this profusion's adjunct, this acceleration's accompaniment.

In this regard, Deleuze and Guattari are as precise and succinct as possible.

A line of becoming is not defined by points that it connects, or by points that compose it; on the contrary, it passes between points, it comes up through the 
middle. ... A point is always a point of origin. But a line of becoming has neither beginning nor end, departure nor arrival, origin nor destination; to speak of the absence of an origin, to make the absence of an origin the origin, is a bad play of words. A line of becoming has only a middle ... it is the absolute speed of movement ... the in-between, the border. (2004, 323; italics in the original)

In the face of this aporia of origins and destinations, the task the radical philosophy of Deleuze and Guattari sets out is at once much simpler and more challenging. The task consists of constructing a plane of immanence (sometimes also called a plane of consistency) that gathers all the dimensions, all the assemblages on a smooth, unstratified, deterritorialized, flat surface in such a way that all the becomings involved, all the crossovers and intersections, all the differences assembled are given due prominence and free rein to announce themselves, unencumbered as they are from unduly deterministic and reductionist temperaments. 'Can a given multiplicity flatten and conserve all its dimensions in this way, like a pressed flower that remains just as alive dry?' they ask $(2004,277)$. For ethnographers that strive to keep their experiences alive when transporting them to the dry page, this is the most apposite challenge and the task which I now turn to. 